ORIENTAL JOURNAL OF
ISSN: 0974-6471
June 2017,
COMPUTER SCIENCE \& TECHNOLOGY
$\begin{gathered}\text { An International Open Free Access, Peer Reviewed Research Journal } \\ \text { Published By: Oriental Scientific Publishing Co., India. }\end{gathered}$
www.computerscijournal.org

\title{
Geographical Information Based Expert System to Estimate Submersible Pump System Specifications
}

\author{
GURPREET KAUR $^{1 *}$, DERMINDER SINGH ${ }^{1}$ and RAJAN AGGARWAL ${ }^{2}$
}

${ }^{*}$ Corresponding author E-mail: gurpreet-seeit@ pau.edu

http://dx.doi.org/10.13005/ojcst/10.02.34

(Received: May 18, 2017; Accepted: June 06, 2017)

\begin{abstract}
During past two decades, groundwater utilization has increased tremendously in the state of Punjab (India) particularly for agriculture purposes. Higher energy demand for lifting water is a result of decline in water table. Punjab is presently facing water crises which exasperate monetary conditions of small farmers, abrogate the natural value and unfavorably influence farming generation and economy of the state. In this research, an expert system was developed using Java Standard Edition 7 which provide appropriate selection of submersible pump set and required associated components such as power cable rating and size, generator capacity, ammeter rating, voltmeter rating, capacitor rating and Polyvinyl Chloride pipe diameter based on the spatial information of last 18 years (1998-2015) of ground water table for the state of Punjab. The developed system will be beneficial for the farmer's in estimation of the required submersible pumping system and allied electrical components.
\end{abstract}

Keywords: geographical information system; submersible pumping system; expert system.

\section{INTRODUCTION}

Groundwater pumping in the agricultural sector increased in Punjab state to meet the growing needs of agricultural sector. Both surface and ground water contribute towards irrigation; however surface water supply being inadequate, ground water is the main source of irrigation. Also the increased exploitation of ground water is due to cultivation of high water consuming crops in most parts of the state. Escalated need of water means has created an issue of deterioration or declination of water table depth and higher energy demand for lifting water as a result of decline in water table depth. The statistic of tube wells has grown from 6.0 lakh in 1980 to 14.06 lakh in 2015'. Up to 1995 , the normal fall of water table in Punjab was around 23 $\mathrm{cm}$ for each year ${ }^{2}$ which amid the following 6 years (1997-2003) expanded to $53 \mathrm{~cm}$ for every year ${ }^{3}$ and was around $51.5 \mathrm{~cm}$ for every year amid 1998 to $2006^{4}$.

Pumps pull water from wells or surface sources. It is important to analyse the system precisely so as to make it as valuable and economical while as yet meeting the water system 
prerequisites. Estimated life spans for most of the pumps, regardless of their type or type of well in which it is install, ranges from 5 to 30 years.

Farmers are facing a problem in selection of pump sets and its components because of lack of knowledge about pumping system. This leads to ineffective use of pumps to irrigate fields. Wrong selection of pump sets and its components may lead to failure in components and sometime the whole bore well fails which results in enhanced cost. If the pump performance specifications are not coordinated with site working conditions, it may lead to consequences that affect safety, dependability, capital cost, operational expenses and so forth.

Submersible pumps much of the time requires smaller drop pipe than do line shaft pumps since the full area of the pipe is utilized to deliver water to the surface. Over size pumps generally results in wastage of energy. This results in not only increase in the cost of pumping water but also has adverse effect on ground water resources. Whereas going for under capacity pumping unit affects the yield of crops because of non-fulfilment of irrigation requirement. If the pump is properly selected, maintained and no unusual conditions occurred in pumping, it is quite possible that the pump and its allied component have longer effective life.

Geographical Information System (GIS) tool is utilized to examining spatial data from various disciplines. It incorporates, analyze and represent spatial information and database of any resource, which could be effectively utilized for resource improvement arranging, ecological assurance and logical inquiries. GIS have been utilized for a variety of groundwater studies. Therefore, this system will be beneficial for farmer's community in estimation of the required submersible pumping system.

In the present work a GIS based expert system is proposed to estimate submersible pump system for a particular site. The system helps to provide an appropriate selection of submersible pump set and allied components such as power cable size, generator capacity, ammeter /voltmeter rating, capacitor rating and Polyvinyl Chloride (PVC) pipe diameter based on the spatial information for the state of Punjab.

\section{MATERIALS AND METHODS}

Punjab covers a geographical area of 5.0362 Mha and extends from $29.30^{\circ}$ North to $32.32^{\circ}$ North latitudes and $73.55^{\circ}$ East to $76.50^{\circ}$ East longitudes.

\section{Pumping specification and its allied components Required discharge (Q)}

Discharge required fulfilling the irrigation water demand, which depends on the area to be irrigated, cropping pattern and groundwater behaviour. By knowing the size of field and water table depth for irrigation discharge can be calculated. But favoured values for discharge for non-paddy crop is $1.25 \mathrm{l} / \mathrm{s}$ and for paddy crop 1.5 times more than non-paddy crop i.e. $1.875 \mathrm{l} / \mathrm{s}^{5}$.

\section{Total head (h)}

The total head is a sum of water table depth, 20 percent as losses (frictional, pipe bends and fitting losses) and draw down.

$$
h()=1.2 *(h)+(3)
$$

Value of draw down is taken $3 \mathrm{~m}$ for an average water table depth and general conditions ${ }^{5}$. Rise/fall was also considered depending upon the effective life span of pump in present study ${ }^{5}$.

\section{Required horse power (hp)}

Horse power depends upon the discharge required and total head.

$\mathrm{hp}=\left(2^{*}\right.$ discharge required * total head $) / 76$

\section{Wire length}

Wire length is calculated by sum of water table depth, surface distance to starter panel, slack allowance and some extra.

$h()+(6)+(12.19)+()=h$

Rise/fall was also considered for measuring of wire length.

\section{PVC pipe diameter}

For calculating PVC pipe diameter, 
initially calculate the area of pipe. Area of pipe was dependent upon the discharge $(m)$ and velocity (permissible velocity of flow).

$\mathrm{h}()=(1.5 /)$

Then, calculate the diameter of PVC pipe by,

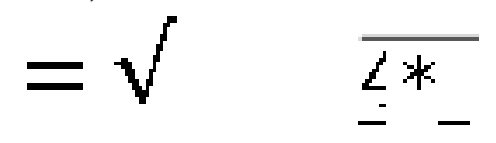

Power cable wire diameter

Power cable wire diameter for required submersible pump is suggested as per selection guide for three core flat cables provided by- Fino lex company ${ }^{6}$. Further, as per submersible pump depth, wire diameter is also suggested as per guide provided by- Franklin Electric ${ }^{7}$.

\section{Generator capacity}

Diesel engine generator set has adequately selected to meet the load requirements of selected submersible pump. The generator capacity for the required submersible pump has been suggested as per application, installation and maintenance guide - Franklin Electric ${ }^{7}$.

\section{Ammeter rating}

Current drawn by single phase or three phase submersible pump is selected as per guide provided by-Franklin Electric ${ }^{7}$. ammeter $=5 * \mathrm{I}(\mathrm{A})$

Where I =line current drawn by specific submersible motor.

\section{Voltmeter rating}

Voltmeter adequately rated to satisfy the voltage requirements of submersible pumps. For single phase voltage required is $230 \mathrm{~V}$ and for three phase required voltage of submersible pumps is $400 \mathrm{~V}$, as is suggested by Franklin Electric ${ }^{7}$.

$=1.5^{\star}()$

Where $\mathrm{V}_{\mathrm{L}}=$ line voltage of submersible pump set.

\section{Capacitor rating}

Capacitors are required to compensate reactive power of inductive load such as submersible pump. Capacitor rating is suggested as per required submersible pump as per guide provided by the Franklin Electric ${ }^{7}$.

\section{Software Requirement}

For the implementation of proposed expert system, Java Standard Edition (Java SE) was used along with My Structured Query Language5.5 (MySQL) and derby10.8 database. Java SE is a widely used platform for the deployment and development of portable code. Further, parsing of shape files is done using Geo Tools 13.2 java code

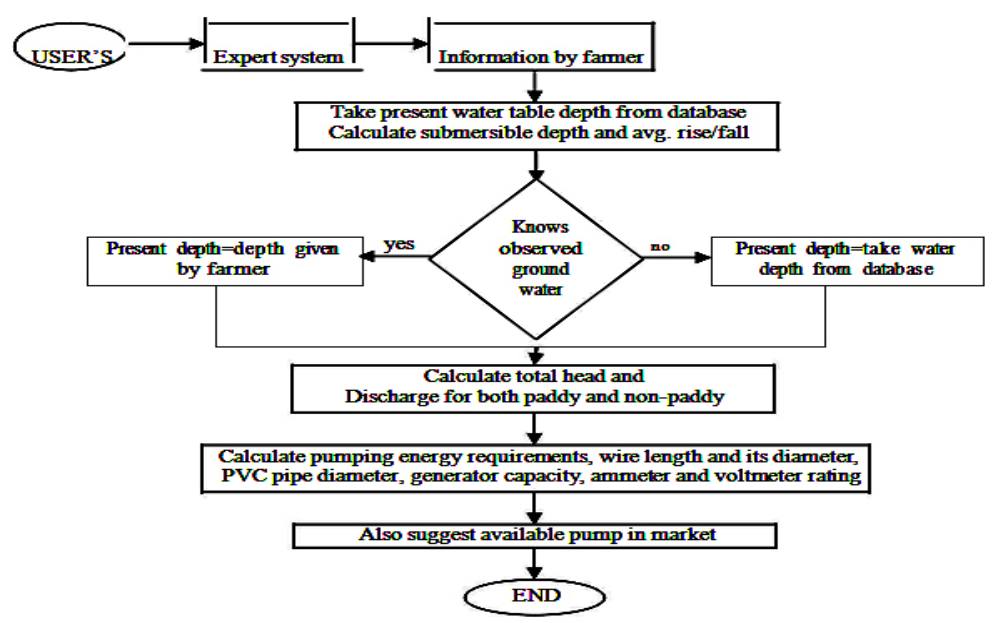

Fig. 1: Flowchart for estimating submersible pump specification for both offline and online standalone applications 
library. A shape file stores non topological geometry and attribute information for the spatial features in a data set. The geometry for a feature is stored as a shape comprising a set of vector coordinates. Geo Tools is an open source (LGPL) Java code library which provides standards compliant methods for the manipulation of geospatial data. Flowchart of expert system is shown in Fig.1. Two applications were developed:

Flowchart for estimating submersible pump specification for both offline and online standalone applications

\section{RESULTS AND DISCUSSION}

\section{Offline standalone application}

Derby is a full-highlighted, open source Relational Database Management System (RDBMS) that depends on Java technology and SQL. Derby is fully written and implemented in the Java programming language. Derby offers users a

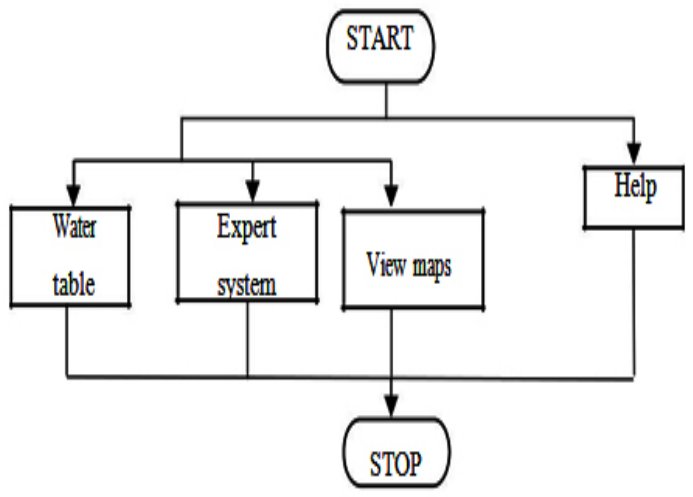

Fig. 2: Work flow diagram of offline standalone application

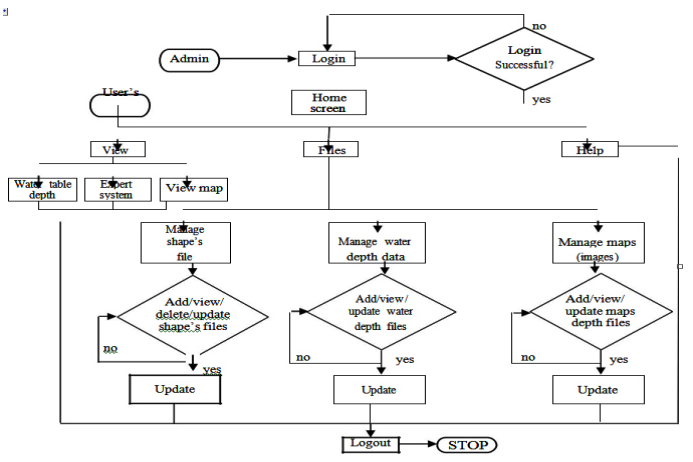

Fig. 3: Work-flow diagram of online standalone application small-footprint standard-based database engine, which can be tightly embedded in any Java-based solution, there is no separate database server installed or maintained by the end user. This proposed system is used by farmers. Work flow diagram for offline standalone application is shown in Fig.2.

\section{Work-flow diagram of offline standalone application.}

Online standalone application

(requiring internet access)

MySQL is the leading open source Database Management System (DBMS). It is a multi-user, multi threaded DBMS used with Java and other programming languages. Structured Query Language (SQL) database is the most popular language to add access and manage database. It is most notable for its quick processing, proven reliability, ease and flexibility of use. File Transfer Protocol (FTP) is a standard Internet Protocol (IP) to transmit files between computers on the Internet. The proposed system is intended for two types of users: Administrator and Farmer. In our case administrator will be a domain expert and user will be a farmer. Work-flow diagram of the application is shown in Fig.3.

\section{Work-flow diagram of online standalone application}

Initially, expert system for estimation window demanded some information to be filled by the farmer such as area under paddy, area under non-paddy and by selecting year of installation

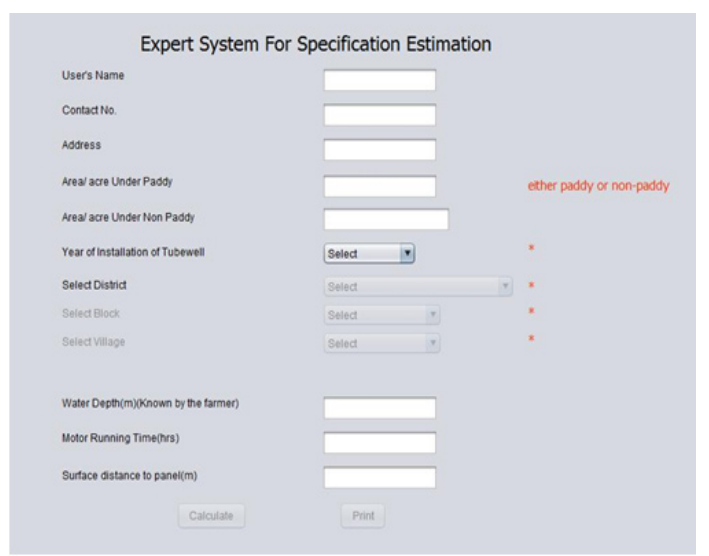

Fig. 4: Expert system form with inputs 


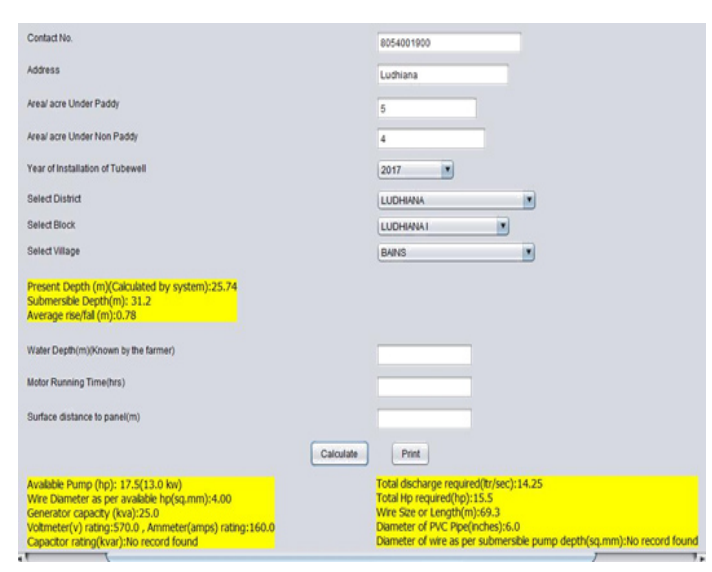

Fig. 5: Results produced by expert system

of tube well, district, block and village name as shown in fig.4. After selecting village some results were appeared on screen such as present depth, submersible depth for design and average rise/fall in groundwater. After clicking on calculate button, results are suggested for submersible pumping system such as total discharge required, $h p$ required, available pump in market, wire diameter, wire length, generator rating, capacitor rating and voltmeter rating as shown in fig.5.

\section{Expert system form with inputs Fig.5 Results produced by expert system Conclusions}

The proposed expert system has been developed in an efficient and effective way. System analysis of the expert system involves comparing shortcomings of the existing physical expert advisory system and its practical usage to the advantages of the standalone application which does not require a physical meeting. So, this system will be beneficial for farmer community by providing precise specification of submersible pumps and its allied components. The aim has meet successfully the system will provide decisions about submersible pumps.

\section{REFERENCES}

1. Anonymous, Statistical abstract of Punjab

Directorate of Economics and Statistics, Government of Punjab, Chandigarh 2015. [Online]. Available http://www.esopb.gov.in/ static/ PDF/Abstract\%202015.pdf.

2. Khepar, S.D., Sondhi, S.K., Chawla, J.K. and Singh, M. Impact of soil and water conservation works on ground water regime in Kandi area of Punjab. J Soil Water Conserv., 2001; 45: 182-89.

3. Hira, G.S., Jalota, S.K. and Arora, V.K. Efficient management of water resources for sustainable cropping in Punjab. Research Bulletin. Department of Soil, Punjab Agricultural University, Ludhiana, Punjab 2004; pp 20.
4. Kaur, S., Aggarwal, R. and Soni, A. Study of water-table behaviour for Indian Punjab using GIS.

Water Sci. and Tech. 2011;63:1574-81.

5. Aggarwal, R. Proper installation of pumps conserve energy. Progressive farming 2011; 47(1):15-34.

6. Anonymous, Winding wire and 3 core flat cables 2010.[Online]http://www. finolex.com/UserFiles/Fi le/Winding\%20 WireleafletMar\%2010for\%20Web. pdf

7. Anonymous, $50 \mathrm{~Hz}$ Submersible motorsApplication, Installation and Maintence Guide 2016.[Online]Availablehttp://www. franklinwater. com/media/123156/50_HZ_ AlM.pdf. 